\title{
Variabilidad espacial de la mortalidad general y características económicas en el Estado de México*
}

\author{
Recibido: 20 de marzo de 2020 - Aprobado: 18 de junio de 2020 \\ https://doi.org/10.22395/seec.v23n54a14
}

Giovanna Santana Castañeda**

\section{RESUMEN}

El propósito de este trabajo es analizar la variabilidad espacial de algunos indicadores económicos seleccionados. Para ello, se toma como variable dependiente la tasa de mortalidad general en el Estado de México para localizar municipios prioritarios en función de los diferentes sectores de actividad económica. El método que se aplicó fue la regresión geográficamente ponderada (GWR por sus siglas en inglés), que permite identificar de manera espacial los municipios donde se tiene que combatir la desigualdad e inequidad económica y de salud que sufren las familias mexiquenses. El resultado expone la manera en que dichos indicadores se relacionan y varían en el territorio. Se encontró que existe variabilidad espacial en nueve indicadores de los once seleccionados, de manera espacial las condiciones desfavorables se encuentran en municipios rurales localizados al suroccidente de la entidad.

\section{PALABRAS CLAVE}

Salud y desarrollo económico; modelos econométricos; modelos espaciales.

\section{CLASIFICACIÓN JEL}

\author{
I12
}

\section{CONTENIDO}

Introducción; 1. Aspectos teóricos; 2. Metodología; 3. Resultados; 4. Conclusiones; Bibliografía.

\footnotetext{
El presente artículo es parte de un proyecto en curso desde hace un par de años, cuyo propósito es analizar y tratar de explicar el espacio geográfico y las interacciones que existen entre diversos factores ambientales, sociales y económicos. Estos resultados apoyarán a la toma de decisiones efectiva en el ámbito de la salud pública. Tipo de artículo: investigación. Cuerpo académico 157: Geografía, ordenación y gestión sustentable del territorio. Nombre del proyecto: Observatorio geográfico: salud y riesgos en México, Conacyt.

** Geoinformática y maestra en Análisis Espacial y Geoinformática, Universidad Autónoma del Estado de México, Toluca, México. Doctora en Geografía, Universidad Nacional Autónoma de México, Ciudad de México, México. Profesora investigadora de la Facultad de Geografía, Universidad Autónoma del Estado de México, Toluca, México. Cuerpo académico: Geografía, ordenación y gestión sustentable del territorio. Correo: gsantanac@uaemex.mx. Orcid: https://orcid.org/0000-0003-4828-8325
} 


\title{
Spatial Variability of Common Death and Economic Characteristics in the State of Mexico
}

\begin{abstract}
The purpose of this piece of work is to analyze the spatial variability of some economic indicators previously selected, taking as a dependant variable the general mortality rate in the State of Mexico to locate priority municipalities regarding the different sectors of their economic activities. The method applied was the GWR (Geographically Weighted Regression), which allows the identification of those municipalities in which health and economic inequality among Mexican families needs to be attended. The result exposes how those indicators are related and vary within the territories, finding that there is spatial variability in nine indicators out of the eleven selected, especially the unfavourable conditions are found in rural municipalities located to the southeast of the entity.
\end{abstract}

\section{KEYWORDS}

Health and economic development; econometrical models; spatial models.

JEL CODE

I1 2

\section{CONTENTS}

Introduction; 1. Theoretical aspects; 2. Methodology; 3. Results; 4. Conclusions; Bibliography.

\section{Variabilidade espacial da mortalidade geral e características econômicas no Estado do México}

\section{RESUMO}

O objetivo deste trabalho é analisar a variabilidade espacial de alguns indicadores econômicos selecionados, tomando como variável dependente a taxa de mortalidade geral no Estado do México, para localizar municípios prioritários em função dos diferentes setores de atividade econômica. O método aplicado foi a regressão geograficamente ponderada (GWR, por sua sigla inglês), que permite identificar, de maneira espacial, os municípios onde se tem que combater a desigualdade e inequidade econômica e sanitária que as famílias do México sofrem. O resultado expõe a maneira em que esses indicadores estão relacionados e variam no território; além disso, verificou-se a existência de variabilidade espacial em 9 dos 11 indicadores selecionados; da perspectiva espacial, as condições desfavoráveis se encontram em municípios rurais localizados no sudoeste da entidade.

\section{PALAVRAS-CHAVE}

Saúde e desenvolvimento econômico; modelos econométricos; modelos espaciais.

\section{CLASSIFICAÇÃO JEL}

112

\section{CONTEÚDO}

Introdução; 1. Aspectos teóricos; 2. Metodologia; 3. Resultados; 4. Conclusões; Bibliografia. 


\section{INTRODUCCIÓN}

La mortalidad es un proceso natural en la vida de los seres vivos, se analiza a través de estimaciones como la tasa de mortalidad general (TMG) cuya fórmula es aplicada a datos de los registros de defunciones en relación con el total de población de un lugar y en un periodo determinado. El Estado de México ha experimentado una disminución considerable, puesto que en el año 1950 la TMG se estimaba en 22,6 defunciones por cada mil habitantes y para el año 2000 la entidad registró la menor tasa: 4,2 defunciones. Sin embargo, en los años posteriores la tasa ha ido en aumento. En 2005 la tasa se fijó en 4,4; en 2010 en 4,7 y para el año 2015 en 4,9. Los factores que han traído este aumento son diversos: los directos como los biológicos, los ambientales, las enfermedades, entre otros; y los indirectos como las características sociales y económicas de la población; la ineficiencia de los servicios de salud; la mala calidad y espacio de la vivienda, la violencia en general, etc. No obstante, las características económicas tienen una repercusión directa al momento de combatir una situación adversa que aqueja la vida de la población, es decir, entre menos carencias, mayor posibilidad de aumentar los años de vida. Cabe destacar que no siempre es así, pero es una hipótesis planteada a partir de la consulta bibliográfica.

Por lo anterior, contar con datos de mortalidad y económicos de la población, representarlos cartográficamente y analizarlos representa una fuente de información geográfica que, a la postre, debe ser referente para los tomadores de decisiones al momento de la creación de planes de desarrollo municipales. Esto se hace con el fin de localizar los lugares prioritarios para atender las carencias que presente la población de cada sector de actividad económica y que se relacionan con la mortalidad general.

\section{ASPECTOS TEÓRICOS}

\subsection{Geografía de la salud}

La geografía de la salud tuvo gran influencia del paradigma neopositivista que hizo que los temas de localización formaran parte de los estudios de geografía médica. El estudio de la distribución y accesibilidad de los equipamientos sanitarios y los servicios médicos llega a representar el $30 \%$ de las investigaciones a principios de los años ochenta. Este nuevo contenido, sumado al tradicional medioambiental físico, motivó un cambio de denominación de la disciplina propuesto por la Comisión de Geografía Médica de la UGI, en el Congreso de Moscú (1976), que pasó a denominarse desde entonces geografía de la salud, como agregado de los contenidos de geografía médica y de los servicios sanitarios (Olivera, 1993). Perdomo y Cuartas (2010) señalan que: 
Se apoya en la geografía cuantitativa y en el desarrollo de modelos predictivos que permiten simular situaciones ambientales y los factores sociales relacionados con estas, sinergia que puede producir determinadas enfermedades en contextos espaciales específicos. Tiene como objetivo mejorar el bienestar social de las poblaciones a través del conocimiento de la situación en salud, el cual debe ser interpretado en la búsqueda de actuaciones o intervenciones desde los organismos encargados de erradicar o disminuir aquellas enfermedades que se anteponen a ese bienestar de la población. (p. 17)

Actualmente, la geografía de la salud no solo tiene un enfoque geográfico sobre cuestiones de salud, sino que es una ciencia aplicada a la salud, que se constituye en un movimiento generoso de oferta de conceptos y métodos empleados para comprender y actuar sobre los problemas de salud. La diversidad de temas es resultado de los diversos campos de actuación de la salud colectiva, que comprenden las acciones de vigilancia de enfermedades, la atención a la salud y la promoción de salud. Estudiar estos problemas requiere una visión ampliada de salud, que abarque desde la prevención de enfermedades hasta el acceso a servicios de salud, esto es, sobre el proceso inseparable de salud-enfermedad-atención (Barcellos, Buzai y Santana, 2018).

Santana, Rosales y Santana (2016) enuncian que la geografía de la salud ofrece un campo vasto de aplicación para estudios locales, regionales y globales. En este sentido, abordan temáticas sobre morbilidad, mortalidad, servicios de salud y los factores que inciden en ellos. Además, expresa que el uso de las geotecnologías cobra mayor importancia en los análisis espaciales y como apoyo para la toma de decisiones.

\subsection{Análisis espacial en geografía de la salud}

El análisis espacial de estas condiciones es un instrumento de gran valor en la evaluación del impacto en procesos y estructuras sociales, así como en la determinación de eventos de salud. La categoría espacial tiene un valor intrínseco en el análisis de las relaciones entre salud, sociedad y ambiente. Conocer la estructura y dinámica espacial de la población permite la caracterización de situaciones de salud. Además, permite el planeamiento de acciones de control y localización de recursos. Barcellos (2003) y Buzai (2015, p. 215) señalan que:

La salud humana y los servicios sanitarios conforman actualmente una de las relaciones más dinámicas de los estudios de la dimensión espacial en un campo de gran sensibilidad social donde la geografía presenta importantes aptitudes para su estudio. El espacio geográfico es un nivel focal en el que se combinan ciencia, metodología y tecnología para el abordaje espacial de las enfermedades que afectan a la población. (p. 215) 
Ramírez Mita (2005, p. 4) explica que el empleo de los sistemas de información geográfica (SIG) se asocian con diferentes cuestiones que tienen que ver con alguna descripción espacial de un evento de salud; con alguna situación en un área geográfica en una población específica; con el análisis de patrones de la distribución en la situación de salud de distintos niveles de agregación; la identificación de grupos vulnerables; con la vigilancia y monitoreo en salud pública; con la identificación de riesgos ambientales y ocupacionales, entre otros (gráfico 1).

\section{Gráfico 1. Análisis espacial en geografía de la salud}

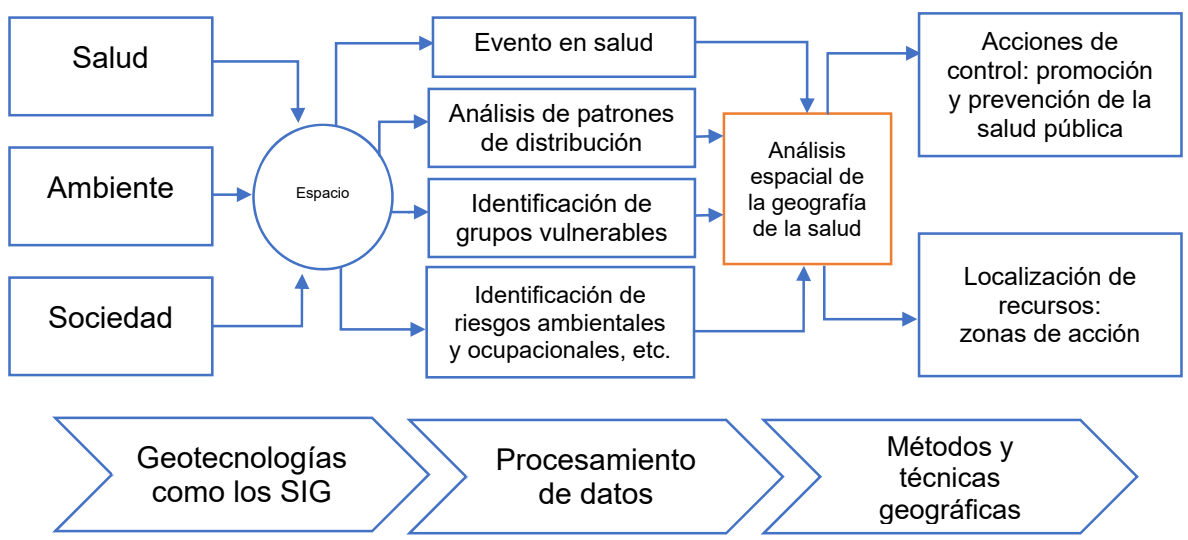

Fuente: elaboración propia con base en Barcellos (2003); Barcellos, Buzai y Santana (2018); Buzai (2015) y Ramírez Mita (2005).

\subsection{Mortalidad y factores económicos}

Muchos países desarrollados han analizado la mortalidad y su relación con distintos grupos socioeconómicos y ocupacionales mediante la utilización de estadísticas vitales. Inglaterra es el país con mayor tradición en elaborar este tipo de análisis de forma sistemática. Ya desde 1855 se publican cada decenio tablas de mortalidad por diferentes grupos ocupacionales (Casi Casanellas y Moreno Iribas, 1992). Por su parte, Mackenbach et al. (2017) sostienen que

las desigualdades en cuanto a la mortalidad y la morbilidad entre las personas con una posición socioeconómica alta o baja, según el nivel educativo, la clase ocupacional o el nivel de ingresos, son un desafío persistente para la política sanitaria. (p. 44)

Carneiro de Oliveira et al. (2010) señalan que:

Las desigualdades en salud tienen su origen en las desigualdades políticas, económicas y sociales que existen en la sociedad. El desarrollo y el crecimiento 
económico de los países han dado como resultado altos niveles de industrialización y urbanización, pero también han creado sociedades profundamente marcadas por las desigualdades, que causan un exceso de mortalidad y de morbilidad superiores a la mayoría de los factores de riesgo de enfermar conocidos. (p. 442)

Estos mismos autores sugieren que las variaciones en los valores de mortalidad se pueden explicar a partir de la desigualdad en los factores de carácter conductual (como fumar, consumir bebidas alcohólicas, etc.), aunado a la disparidad en los factores estructurales (pobreza y política económica nacional, condiciones culturales, etc.) y que estos contribuyen a las variaciones entre países en la misma magnitud de las desigualdades socioeconómicas en la mortalidad. En contraparte, en los países con mayores ingresos económicos y mayor inversión en el sector salud existen menos desigualdades en mortalidad.

\section{METODOLOGÍA}

\section{1 Área de estudio}

El área de estudio (gráfico 2) es el Estado de México,

cuenta con una superficie de $22.351 \mathrm{~km}^{2}$ y se localiza en el centro del país. El clima es templado subhúmedo principalmente, con una temperatura media anual de $14,7^{\circ} \mathrm{C}$ y una precipitación total anual de $900 \mathrm{~mm}$. Colinda al norte con los estados de Querétaro e Hidalgo; al sur con Guerrero y Morelos; al este con Puebla y Tlaxcala; al oeste con Guerrero y Michoacán, así como con la Ciudad de México, al que rodea al norte, este y oeste. (Inafed, 2015).

\section{Gráfico 2. Localización geográfica del área de estudio}

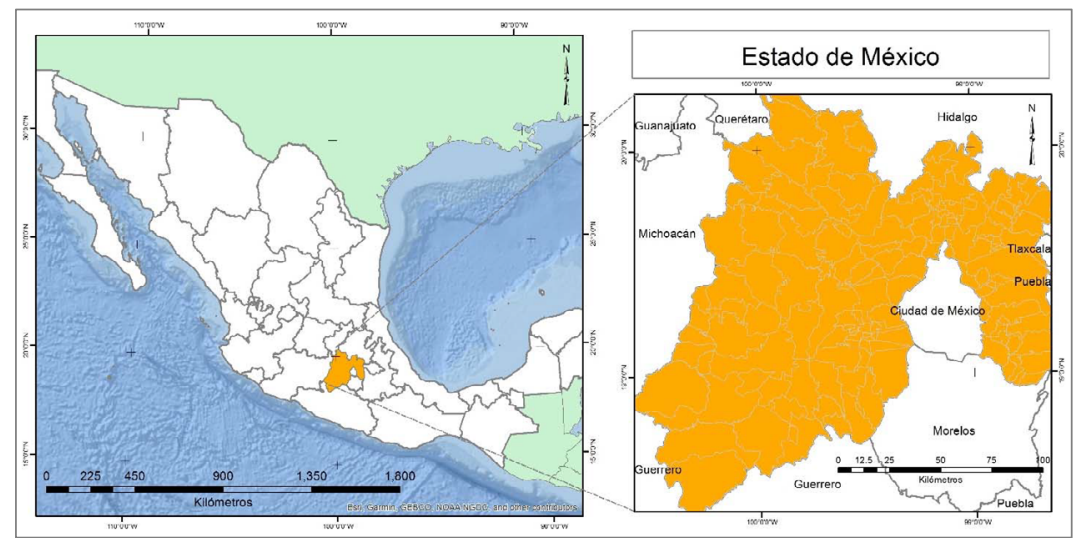

Fuente: elaboración propia en el software ArcMap ${ }^{\circledR}$. 


\subsection{Selección de indicadores}

La relación entre algunas características económicas de la población y la tasa de mortalidad general se han abordado en diversas investigaciones. Para ejemplificar esto, se expone la siguiente tabla. En primera instancia, se presenta la variable dependiente que, en este caso, es la tasa de mortalidad general (TMG). Posteriormente, se enuncian las variables independientes, que son los indicadores económicos. La selección de indicadores se realizó a partir de la consulta bibliográfica y de los indicadores disponibles en el sitio web del Instituto Nacional de Estadística y Geografía (Inegi), fuente principal de información (tabla 1 y gráfico 3).

\section{Tabla 1. Indicadores de estudio}

\begin{tabular}{|c|c|c|}
\hline Indicador & Definición & Fuente \\
\hline Tasa de mortalidad general & $\begin{array}{l}\text { Número de defunciones que ocurren por cada mil } \\
\text { habitantes en un año determinado. }\end{array}$ & Sinais \\
\hline $\begin{array}{l}\text { Porcentaje funcionarios, } \\
\text { profesionistas, técnicos y } \\
\text { administrativos }\end{array}$ & $\begin{array}{l}\text { Funcionarios: realizan actividades directivas, adminis- } \\
\text { trativas, normativas, de planeación y coordinación, en } \\
\text { dependencias y organismos gubernamentales a nivel } \\
\text { nacional, estatal o municipal. } \\
\text { Profesionistas: se caracterizan por haber recibido ins- } \\
\text { trucción y formación profesional en el nivel de escolari- } \\
\text { dad superior (licenciatura, maestría, doctorado, posgra- } \\
\text { do o equivalente) y desempeñar funciones directamente } \\
\text { relacionadas con el tipo de formación recibida. } \\
\text { Técnicos: realizan actividades auxiliares a las de un } \\
\text { profesionista, asesor trabajos de investigación y en la } \\
\text { aplicación práctica de los conocimientos adquiridos en } \\
\text { su campo de especialización. } \\
\text { Administrativos: desempeñan tareas administrativas en } \\
\text { oficinas, fábricas, establecimientos comerciales y de } \\
\text { servicios, etc. }\end{array}$ & Inegi \\
\hline $\begin{array}{c}\text { Porcentaje de trabajadores } \\
\text { agropecuarios }\end{array}$ & $\begin{array}{c}\text { Realizan las actividades propias de la agricultura: ganade- } \\
\text { ría, silvicultura, caza, pesca y la inspección supervisión y } \\
\text { vigilancia del proceso de producción agropecuario. }\end{array}$ & Inegi \\
\hline $\begin{array}{c}\text { Porcentaje de trabajadores } \\
\text { en la industria }\end{array}$ & $\begin{array}{l}\text { Planean, organizan, coordinan, supervisan y controlan } \\
\text { de manera directa los procesos de producción artesanal } \\
\text { e industrial. }\end{array}$ & Inegi \\
\hline $\begin{array}{l}\text { Porcentaje de comerciantes } \\
\text { y trabajadores en servicios } \\
\text { diversos }\end{array}$ & $\begin{array}{l}\text { Se encargan de la compraventa de bienes y servicios, así } \\
\text { como de realizar actividades de promoción, exhibición y } \\
\text { acomodo de mercancías; atender a clientes en servicios } \\
\text { de alquiler. Incluye a los dueños, supervisores y encarga- } \\
\text { dos de establecimientos comerciales. }\end{array}$ & Inegi \\
\hline
\end{tabular}




\begin{tabular}{|c|c|c|}
\hline Indicador & Definición & Fuente \\
\hline $\begin{array}{l}\text { Porcentaje de población en } \\
\text { el sector primario }\end{array}$ & $\begin{array}{c}\text { Comprende: agricultura, ganadería, silvicultura, } \\
\text { pesca y caza. }\end{array}$ & Inegi \\
\hline $\begin{array}{l}\text { Porcentaje de población en } \\
\text { el sector secundario }\end{array}$ & $\begin{array}{l}\text { Comprende: minería, extracción de petróleo y gas, in- } \\
\text { dustria manufacturera, electricidad, agua y construcción. }\end{array}$ & Inegi \\
\hline $\begin{array}{l}\text { Porcentaje de población en } \\
\text { el sector comercio }\end{array}$ & $\begin{array}{l}\text { Es la actividad mediante la cual se intercambian, venden } \\
\text { o compran productos. }\end{array}$ & Inegi \\
\hline $\begin{array}{l}\text { Porcentaje de población en } \\
\text { el sector servicios }\end{array}$ & Comprende: transporte, gobierno y otros servicios. & Inegi \\
\hline $\begin{array}{l}\text { Porcentaje de población con } \\
\text { ingresos de entre uno y dos } \\
\text { salarios mínimos mensuales }\end{array}$ & $\begin{array}{l}\text { Incluye a la población ocupada que tiene ingresos de } \\
\text { entre uno y dos salarios mínimos. }\end{array}$ & Inegi \\
\hline
\end{tabular}

Fuente: elaboración propia con base en el Sistema Nacional de Clasificación de Ocupaciones (Inegi, 2018); Sistema Nacional de Información en Salud (Sinais, 2015) y Clasificación Mexicana de Ocupaciones, CMOHistórica (Inegi, 2020).

\section{Gráfico 3. Esquema metodológico}

\begin{tabular}{|l|l|l|}
\hline Variable dependiente \\
\hline Tasa de mortalidad general \\
\hline Variables independientes \\
\hline $1 \%$ de funcionarios, profesionistas, técnicos y administrativos \\
$2 \%$ de de trabajadores agropecuarios \\
$3 \%$ de trabajadores en la industria \\
$4 \%$ de comerciantes y trabajadores en servicios diversos \\
$5 \%$ de población en el sector primario \\
$6 \%$ de población en el sector secundario \\
$7 \%$ de población en el sector comercio \\
$8 \%$ de población en el sector servicios \\
$9 \%$ de población con ingresos hasta 1 salario mínimo \\
$10 \%$ de población con ingresos de más de 1 a 2 salarios mínimos \\
$11 \%$ de población con ingresos por más de 2 salarios mínimos \\
\hline
\end{tabular}

Fuente: elaboración propia con base en Sánchez (2019, p. 20).

En la modelación, las diferencias en la utilización de un modelo estadístico global y local como GWR se basan en principio por la capacidad de georreferenciación de este último y de representar en un ambiente SIG los resultados con énfasis en las diferencias a través del espacio y en la desagregación local de las estadísticas locales, entre otras (Fotheringham, Brunsdon y Charlton, 2002). 


\subsection{Procesos y etapas}

Para el primer proceso se seleccionó el tipo de modelado lineal entre Gauss, Poisson y logístico. En este caso, el seleccionado fue el gaussiano, que utiliza el esquema de modelado semiparamétrico, donde se habilitó una nueva prueba estadística a los indicadores que varían geográficamente (ecuación 1).

$$
T M_{\text {Gmun }}=\sum_{j=0}^{M} \beta j x i j+\varepsilon i
$$

Ecuación [1]

Donde:

$T M G_{\text {mun }}=$ tasa de mortalidad general en cada municipio (variable dependiente)

$i \quad=1 \ldots \mathrm{N}$ (número de municipios).

$j \quad=0 \ldots M$ (número de variables).

$\beta=$ hace referencia al coeficiente de regresión y $\varepsilon$ a la variable residual.

En el segundo proceso se ajustó el modelado gaussiano con la selección de variables de local a global $(\mathrm{L} \rightarrow \mathrm{G}$ ). Esta realiza una serie de pruebas de comparación de modelos entre el gaussiano y uno nuevo llamado mixto, es decir, los indicadores resaltados en el cuadro de lista no son candidatos para cambiar de un término local a otro global. Con esta rutina se definieron los indicadores que tienen variabilidad espacial (ecuación 2).

$$
\Sigma_{k} \beta_{k}\left(u_{i}, v_{i}\right) x_{k, i}+\Sigma_{\mathrm{l}} \gamma_{\mathrm{l} Z \mathrm{l}, i} i+\varepsilon i,
$$

Ecuación [2]

Donde:

$\Sigma_{k,}$, son los indicadores locales; $\left(u_{i}, v_{i}\right)$, son la x-y coordenada de la ith ubicación; $\Sigma_{\mathrm{L}}$ son los indicadores globales; $z$, $i$ es la th variable independiente con un coeficiente fijo $\gamma$ l. Así, el modelo mezcla geográficamente términos locales y globales.

Por último, se generó la cartografía. En primera instancia, se realizó un mapa del nivel explicativo del modelo mediante el coeficiente de determinación $\mathrm{R}^{2}$, que refleja la bondad del ajuste de un modelo con relación a la variable que se pretende explicar (tabla 2); posteriormente se generaron los mapas de los indicadores que resultaron con variabilidad espacial en el software Arcmap ${ }^{\circledR}$. 
Tabla 2. Nivel explicativo del coeficiente de determinación $\mathrm{R}^{2}$

\begin{tabular}{ccccc}
\hline$<30 \%$ & $30 \%$ a $40 \%$ & $40 \%$ a $50 \%$ & $50 \%$ a $85 \%$ & $>85 \%$ \\
\hline Muy malo & Malo & Regular & Bueno & Sospechoso \\
\hline
\end{tabular}

Fuente: elaboración propia con base en Rojo (2007).

\section{RESULTADOS}

El modelo GWR registró un coeficiente de determinación $\mathrm{R}^{2}$ global de 0,64 , lo que indica que el modelo general es bueno de acuerdo con Rojo (ver tabla 3). Asimismo el criterio de información de Akaike (AICc) es mayor que el clásico (AIC), por lo cual se determina que la calidad del modelo es apropiada (tabla 3).

Tabla 3. Diagnóstico de la información

\begin{tabular}{cc}
\hline Estimación sigma basada en ML & 0,66 \\
\hline Estimación imparcial de la sigma & 0,85 \\
\hline -2 logaritmo de probabilidad & 254,01 \\
\hline AIC Clásico & 336,45 \\
\hline AICc & 378,50 \\
\hline BIC/MDL & 453,03 \\
\hline CV & 1,12 \\
\hline R cuadrada & $\mathbf{0 , 6 4}$ \\
\hline
\end{tabular}

Fuente: elaboración propia en el software GWR4.

Mientras que el coeficiente de determinación $\mathrm{R}^{2}$ local reflejó una bondad de ajuste del modelo bueno en cincuenta y siete municipios que registraron un rango de $51 \%$ a $85 \%$; en veintiséis municipios el modelo resulto regular $(0,41 \%$ a $0,50 \%)$ y en cuarenta y dos fue malo con un rango de $0,39 \%$ a $0,40 \%$ (gráfico 4).

Una vez que se conoce el nivel explicativo de cada municipio observado en el modelo, se procede a analizar la variabilidad espacial de cada indicador local, aunado al nivel de confianza de acuerdo con el valor $t$. De los once indicadores seleccionados, nueve resultaron locales, lo que significa que existe variabilidad espacial. Cabe señalar que se consideran locales cuando los signos del valor mínimo y del máximo son diferentes. 
Gráfico 4. R² local

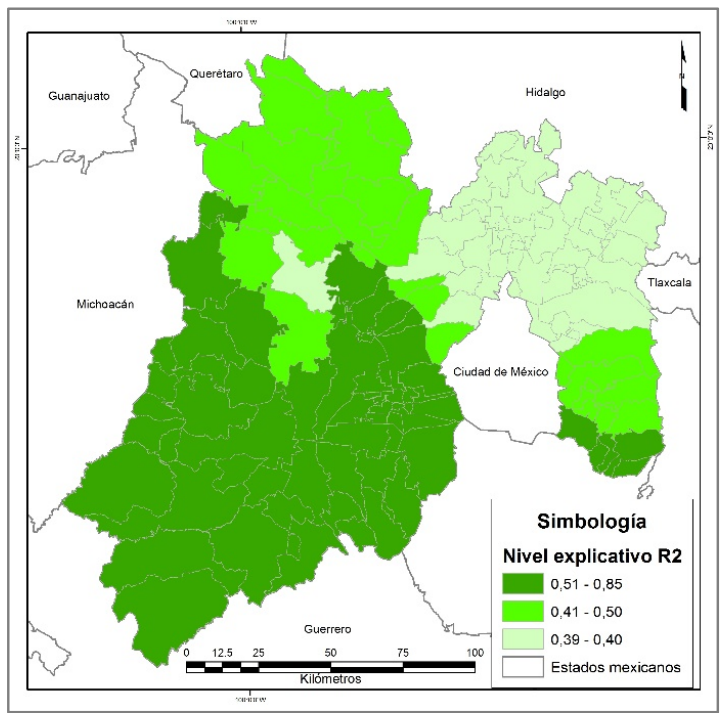

Fuente: elaboración propia en los software GWR4 y ArcMap.

Por otra parte, el intercepto (TMG) tiene valores positivos, tanto en el mínimo como en el máximo, por lo cual, para todos los indicadores se debe interpretar como aumento en la tasa de mortalidad general, además vale la pena mencionar que los valores de significancia para todas las variables son mayores a 0,8 (tabla 4).

Tabla 4. Resumen de estadísticas para variables locales

\begin{tabular}{cccc}
\hline Variable/Indicador & Mínimo & Máximo & Rango \\
\hline Intercepto (TMG) & 4,41 & 5,73 & 1,01 \\
\hline Porcentaje de funcionarios, profesionistas, técnicos y administrativos & $-6,61$ & 10,95 & 17,56 \\
\hline Porcentaje de trabajadores agropecuarios & $-17,88$ & 28,13 & 46,02 \\
\hline Porcentaje de trabajadores en la industria & $-6,25$ & 9,29 & 15,54 \\
\hline Porcentaje de comerciantes y trabajadores en servicios diversos & $-5,65$ & 8,24 & 13,90 \\
\hline Porcentaje de población en el sector primario & $-25,55$ & 17,90 & 43,46 \\
\hline Porcentaje de población en el sector secundario & $-8,01$ & 6,74 & 14,76 \\
\hline Porcentaje de población en el sector comercio & $-5,17$ & 3,75 & 8,92 \\
\hline Porcentaje de población en el sector servicios & $-8,38$ & 7,34 & 15,72 \\
\hline Porcentaje de población con ingresos de entre uno y dos salarios & $-0,10$ & 0,65 & 0,76 \\
\hline mínimos mensuales & & \multirow{2}{*}{0}
\end{tabular}

Fuente: elaboración propia en el software GWR4. 


\subsection{Tasa de mortalidad general con respecto a la distribución porcentual según ocupación: funcionarios, profesionistas, técnicos y administrativos (población ocupada), 2015}

La variable de trabajadores funcionarios, profesionistas, técnicos y administrativos tuvo una relación positiva en treinta y un municipios localizados en el centro y suroriente de la entidad principalmente, dado que la fluctuación en sus coeficientes resultó con valor positivo, lo que indica que varía directamente con la variable dependiente. En consecuencia, esperamos aumento en esa misma variable, que es la tasa de mortalidad general. De ellos, los municipios de Tepetixpa, Ozumba, Ecatzingo, Juchitepec, Atlautla y Huixquilucan deben considerarse prioritarios de atender en este sector de trabajadores, porque sus coeficientes resultaron los más altos $(8,51-10,95)$ con un nivel de confianza de 0,95 .

En contraste, veinticinco municipios localizados al suroccidente principalmente resultaron con relación negativa, dado que sus coeficientes tienen valores negativos. Este hecho indica que, con una disminución en el porcentaje de trabajadores funcionarios, profesionistas, técnicos y administrativos, la tasa de mortalidad general aumenta, es decir, aunque existe una disminución también se espera aumento en la TMG. Por ello, también deben ser considerados prioritarios. Los que presentan las condiciones más negativas son Amatepec, Tlatlaya, Luvianos, Tejupilco y Sultepec porque registraron los coeficientes más altos $(-6.61,-5.62)$ con un nivel de confianza 0,975 . Las ocupaciones de i) funcionarios, profesionistas, técnicos y administrativos, ii) trabajadores agropecuarios, iii) trabajadores en la industria, así como de iv) comerciantes y trabajadores en servicios diversos, que se van a mostrar en los siguientes apartados, comparten un patrón similar, con valores negativos hacia el suroeste del Estado. Muchos de estos municipios se caracterizan por tener un clima templado. A medida que se acerca al sur la temperatura aumenta de semifría a cálida y también disminuye la altitud de más de tres mil a menos de dos mil metros sobre el nivel medio del mar (Conabio, 2020). Por otra parte, los municipios con los valores más altos se caracterizan por presentarse en la zona conurbada a la Ciudad de México y en los municipios de la zona centro del Estado de México se caracterizan por tener mucha población y más localidades urbanas.

El porcentaje de trabajadores agropecuarios tuvo una relación positiva en cuarenta municipios localizados principalmente en el centro y suroriente de la entidad. La fluctuación en sus coeficientes tuvo un valor positivo, lo que indica que varía directamente con la mortalidad. En consecuencia, esperamos aumento en la tasa de mortalidad general. Sin embargo, los municipios de Isidro Fabela, Naucalpán, Atizapán de Zaragoza, Nicolás Romero, Jilotzngo, Tlalnepantla de Baz y Villa del Carbón 
deben considerarse prioritarios para atender este sector de trabajadores, porque sus coeficientes resultaron los más altos $(20,64-28,13)$ con un nivel de confianza de 0,95 . En contraste, veintiséis municipios localizados al suroccidente resultaron con relación negativa, dado que sus coeficientes tienen valores negativos. Esto indica que, con una disminución en el porcentaje de trabajadores agropecuarios, la tasa de mortalidad general aumenta. Esto quiere decir que, aunque existe una disminución, también se espera aumento en la TMG, por lo que deben ser considerados prioritarios. Los que presentan las condiciones más negativas son Luvianos, Otzoloapan, Amatepec, Zacazonapan y Tejupilco porque registraron los coeficientes y el nivel de confianza más alto $-17,88,-11,46$ y 0,995 respectivamente (gráfico 5).

Gráfico 5. Estado de México: GWR. Tasa de mortalidad general con respecto a la distribución porcentual según ocupación: funcionarios, profesionistas, técnicos y administrativos (población ocupada), 2015

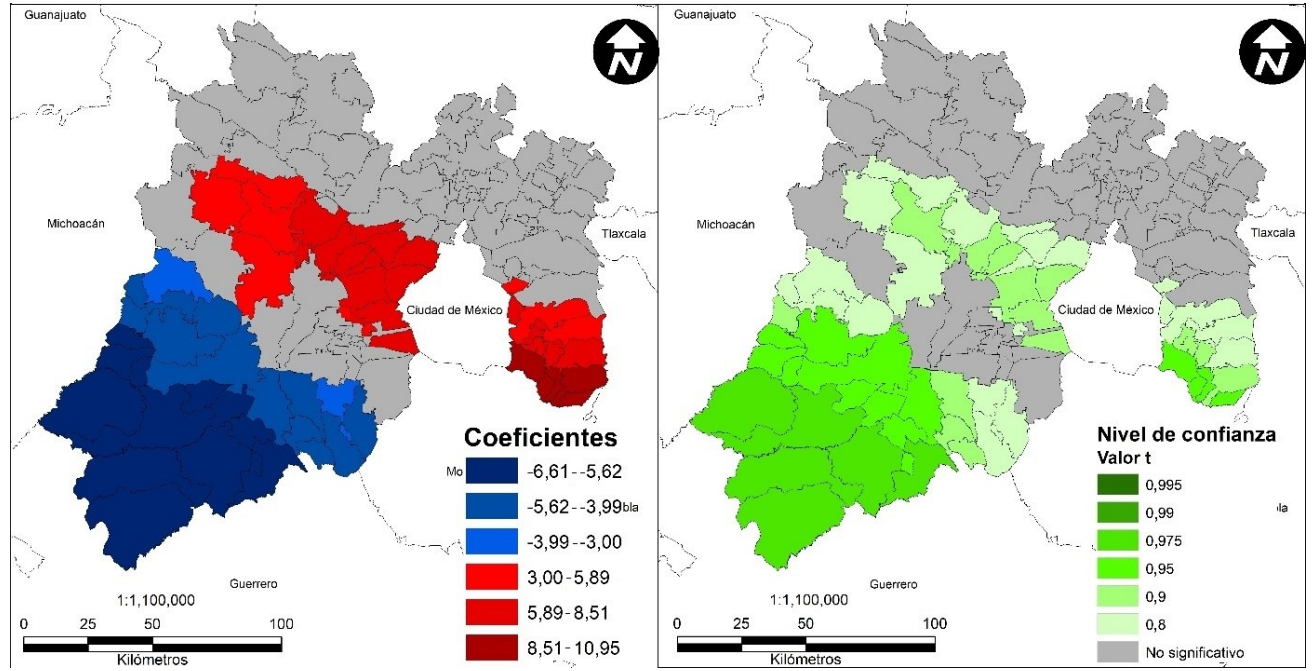

Fuente: elaboración propia en los software GWR4 y ArcMap.

3.2 Tasa de mortalidad general con respecto a la distribución porcentual según ocupación: trabajadores agropecuarios (población ocupada), 2015

En el gráfico 6 se muestra la tasa de mortalidad según el grupo poblacional de trabajadores agropecuarios. 
Gráfico 6. Estado de México: GWR. Tasa de mortalidad general con respecto a la distribución porcentual según ocupación: trabajadores agropecuarios (población ocupada), 2015

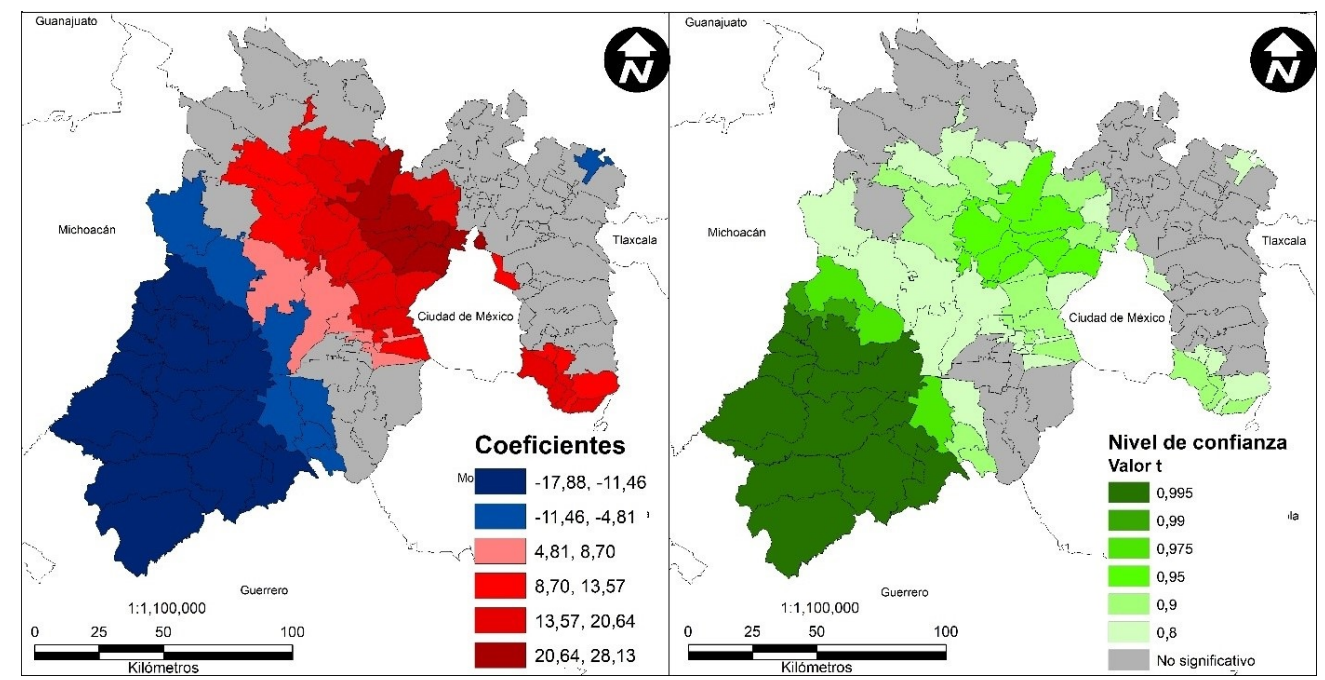

Fuente: elaboración propia en los software GWR4 y ArcMap.

\subsection{Tasa de mortalidad general con respecto a la distribución porcentual según ocupación: trabajadores en la industria (población ocupada), 2015}

El porcentaje de trabajadores en la industria tuvo una relación positiva en veintinueve municipios localizados en el centro y oriente de la entidad. La fluctuación en sus coeficientes resultó con valor positivo, lo que indica que varía directamente con la mortalidad y, en consecuencia, esperamos aumento en la tasa de mortalidad general.

Sin embargo, los municipios de Tepetlixpa, Ozumba, Ecatzingo, Juchitepec, Huixquilucan, Ocoyocac, Atlautla y Lerma deben considerarse prioritarios para atender este sector de trabajadores porque sus coeficientes resultaron los más altos $(7,03-9,29)$ con un nivel de confianza de 0,9. En contraste, veintiséis municipios localizados al suroccidente resultaron con relación negativa. Sus coeficientes tienen valores negativos, lo que indica que, con una disminución en el porcentaje de trabajadores en la industria, la tasa de mortalidad general aumenta. Esto quiere decir que aunque existe una disminución, también se espera aumento en la TMG, por lo que también deben ser considerados prioritarios. Los que presentan las condiciones más negativas son Amatepec, Luvianos, Tlatlaya, Tejupilco, Otzoloapan y Zacazonapan porque registraron los coeficientes más altos $(-6,25,-5,38)$ con un nivel de confianza de 0,975 (gráfico 7). 
Gráfico 7. Estado de México: GWR. Tasa de mortalidad general con respecto a la distribución porcentual según ocupación: trabajadores en la industria (población ocupada), 2015

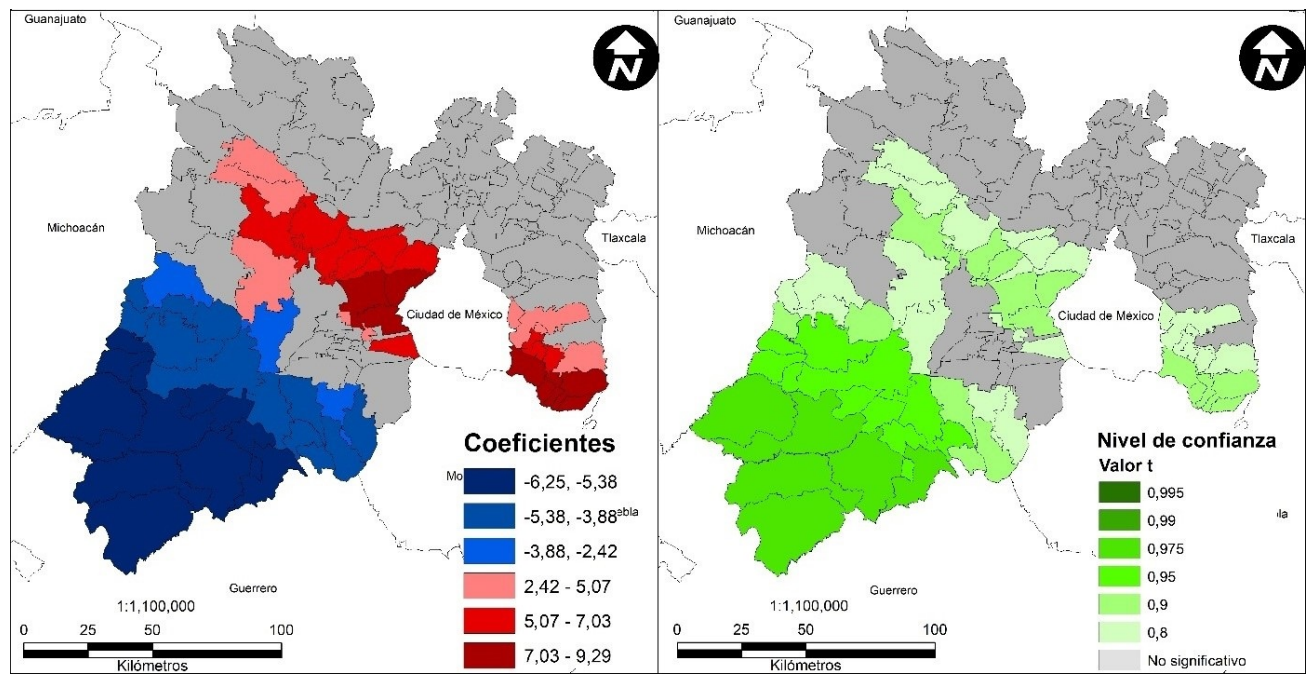

Fuente: elaboración propia en los software GWR4 y ArcMap.

\subsection{Tasa de mortalidad general con respecto de la distribución porcentual según ocupación:} comerciantes y trabajadores en servicios diversos (población ocupada), 2015.

El porcentaje de comerciantes y trabajadores en servicios diversos tuvo una relación positiva en veintisiete municipios localizados en el centro y suroriente de la entidad. La fluctuación en sus coeficientes resultó con valor positivo, lo que indica que varía directamente con la mortalidad y, en consecuencia, esperamos aumento en la tasa de mortalidad general. Sin embargo, los municipios de Tepetlixpa, Ozumba, Ecatzingo, Juchitepec, Huixquilucan, Atlautla y Ocoyocac deben considerarse prioritarios para atender este sector de trabajadores porque sus coeficientes resultaron los más altos $(6,23-8,24)$ con un nivel de confianza de 0,9 . En contraste, veintiséis municipios localizados en el suroccidente resultaron con relación negativa. Sus coeficientes tienen valores negativos, lo que indica que, con una disminución en el porcentaje de comerciantes y trabajadores en servicios diversos, la tasa de mortalidad general aumenta. Esto quiere decir que, aunque existe una disminución, también se espera aumento en la TMG. Por ello también deben ser considerados prioritarios. Los que presentan las condiciones más negativas son Amatepec, Tlatlaya, Luvianos, Tejupilco, Sultepec y Zacualpan porque registraron los coeficientes más altos $(-5.65,-4.85)$ con un nivel de confianza de 0,975 (gráfico 8). 
Gráfico 8. Estado de México: GWR. Tasa de mortalidad general con respecto a la distribución porcentual según ocupación: comerciantes y trabajadores en servicios diversos (población ocupada), 2015

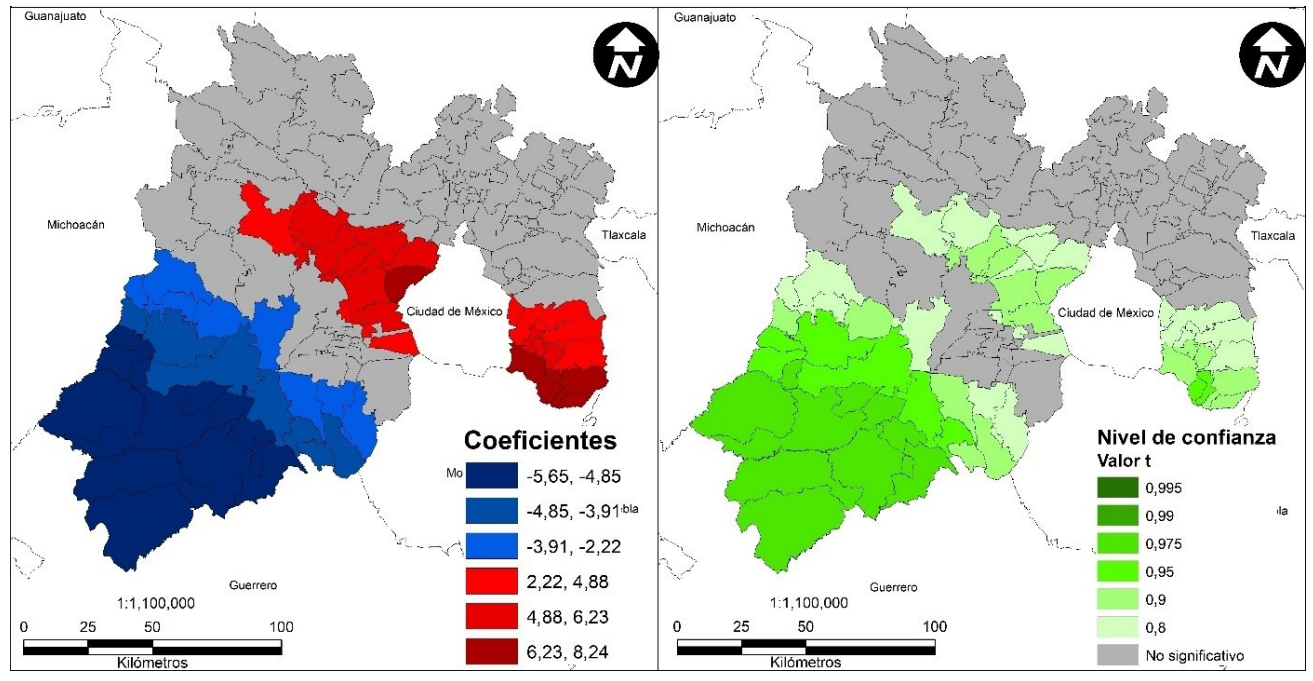

Fuente: elaboración propia en los software GWR4 y ArcMap.

\subsection{Tasa de mortalidad general con respecto a la distribución porcentual según sector de actividad económica: primario (población ocupada), 2015}

El porcentaje de población ocupada en el sector primario tuvo una relación positiva en veintitrés municipios localizados al suroccidente de la entidad. La fluctuación en sus coeficientes resultó con valor positivo, lo que indica que varía directamente con la mortalidad y, en consecuencia, esperamos aumento en la tasa de mortalidad general. Sin embargo, los municipios de Luvianos, Otzoloapan, Santo Tomás, Zacazonapan y Amatepec deben considerarse prioritarios para atender este sector de actividad económica porque registraron los coeficientes y el nivel de confianza más alto $11,95-17,90$ y 0,995 respectivamente. En contraste, cuarenta y cuatro municipios localizados al centro y suroriente resultaron con relación negativa. Sus coeficientes tienen valores negativos, lo que indica que, con una disminución en el porcentaje de población ocupada en el sector primario, la tasa de mortalidad general aumenta. Esto quiere decir que, aunque existe una disminución, también se espera aumento en la TMG, por lo que, también deben ser considerados prioritarios. Los que presentan las condiciones más negativas son Atizapán de Zaragoza, Nicolás Romero, Isidro Fabela, Naucalpan y Tlalnepantla de Baz porque registraron los coeficientes más altos $(-25,55,-19,91)$ con un nivel de confianza de 0,9 y 0,95 respectivamente. 
El patrón que se muestra en los resultados con las variables según actividad económica (1) primaria (gráfico 9), (2) secundaria, (3) comercio y (4) servicios, que se abordarán más adelante, es una distribución inversa a la mostrada con las variables antes mencionadas. Los valores más altos se muestran al suroeste y se caracterizan por tener los grados más altos de marginación (alto y medio).

Gráfico 9. Estado de México: GWR. Tasa de mortalidad general con respecto a la distribución porcentual según sector de actividad económica: primario (población ocupada), 2015

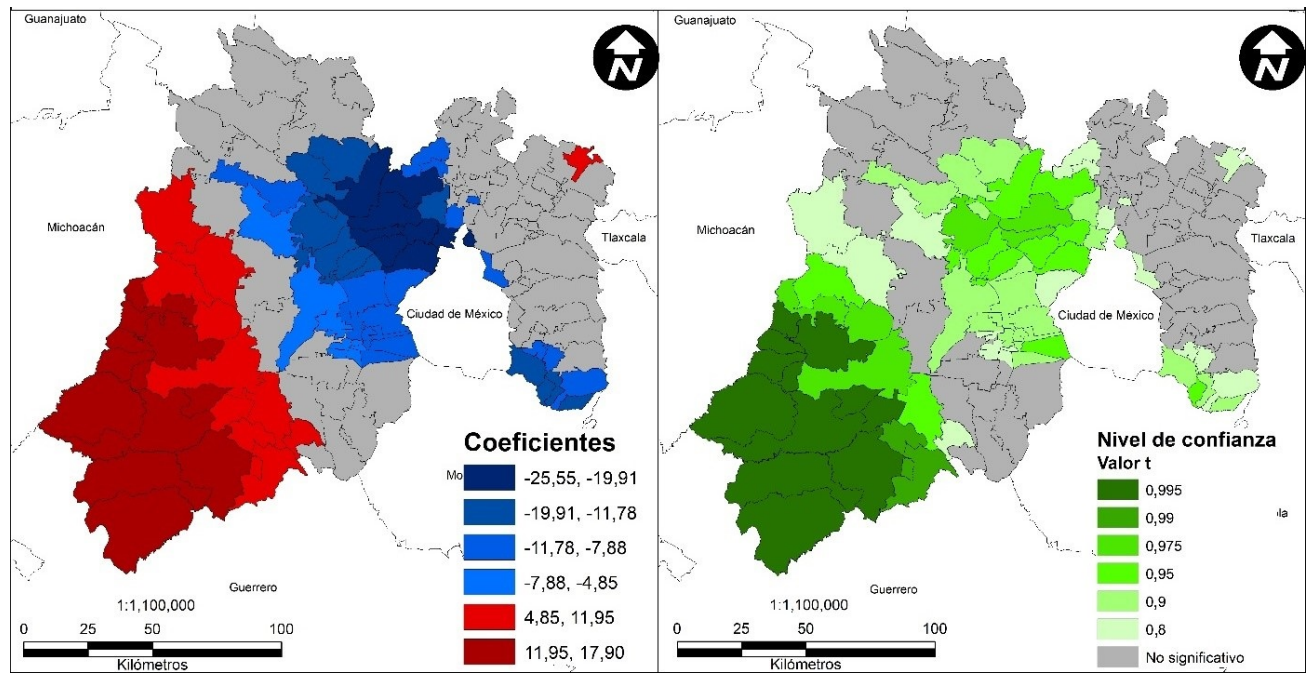

Fuente: elaboración propia en los software GWR4 y ArcMap.

\subsection{Tasa de mortalidad general con respecto a la distribución porcentual según sector de actividad económica: secundario (población ocupada), 2015}

El porcentaje de población ocupada en el sector secundario tuvo una relación positiva en treinta y siete municipios localizados al suroccidente y centroriente de la entidad. La fluctuación en sus coeficientes resultó con valor positivo, lo que indica que varía directamente con la mortalidad y, en consecuencia, esperamos aumento en la tasa de mortalidad general. Sin embargo, los municipios de Luvianos, Amatepec, Otzoloapan, Tlataya y Tejupilco deben considerarse prioritarios para atender este sector de actividad económica, porque registraron los coeficientes más altos (5,456,74 ) con un nivel de confianza de 0,975 . En contraste, doce municipios localizados al suroriente resultaron con relación negativa. Sus coeficientes tienen valores negativos, lo que indica que, con una disminución en el porcentaje de población ocupada en el sector secundario, la tasa de mortalidad general aumenta. Esto quiere 
decir que, aunque existe una disminución, también se espera aumento en la TMG, por lo que deben ser considerados prioritarios. Los que presentan las condiciones más negativas son Tepetlixpa, Ozumba, Ecatzingo, Atlautla y Juchitepec porque registraron los coeficientes más altos $(-8,01,-6,87)$ con un nivel de confianza de 0,9 y 0,95 respectivamente (gráfico 10 ).

Gráfico 10. Estado de México: GWR. Tasa de mortalidad general con respecto a la distribución porcentual según sector de actividad económica: secundario (población ocupada), 2015

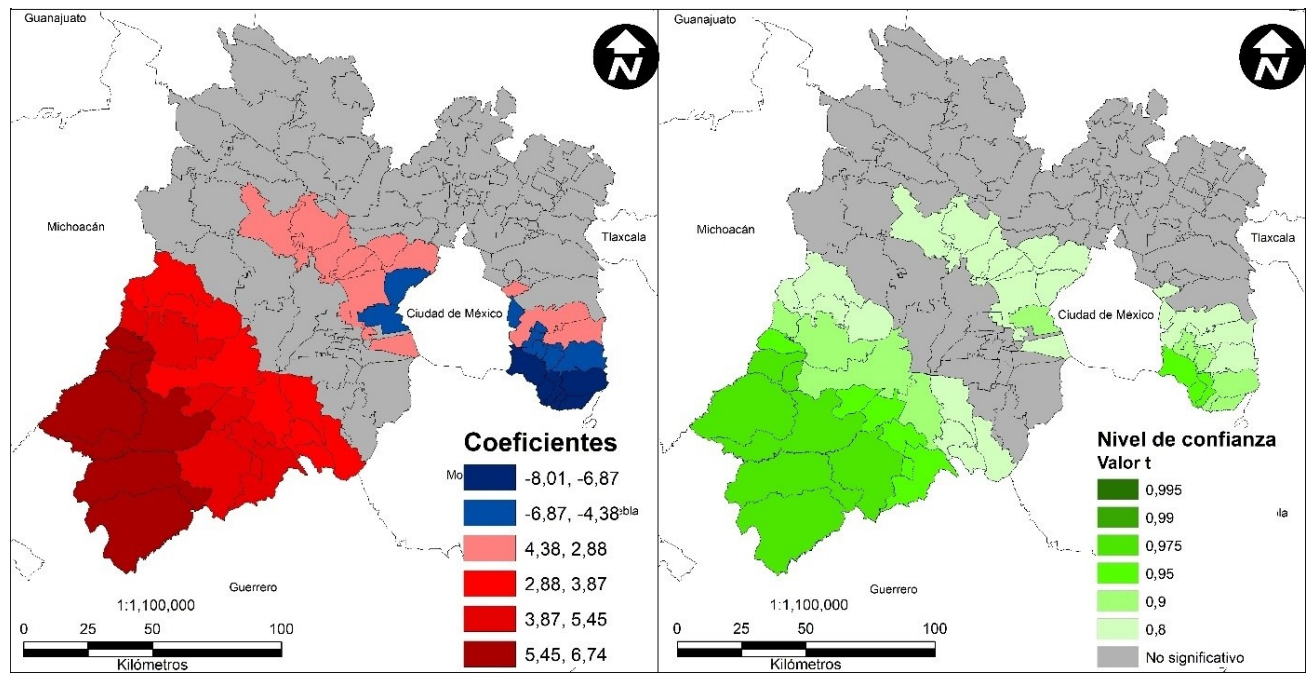

Fuente: elaboración propia en los software GWR4 y ArcMap.

\subsection{Tasa de mortalidad general con respecto a la distribución porcentual según sector de actividad económica: comercio (población ocupada), 2015}

El porcentaje de población ocupada en el sector comercio tuvo una relación positiva en diecinueve municipios localizados al suroccidente de la entidad. La fluctuación en sus coeficientes resultó con valor positivo, lo que indica que varía directamente con la mortalidad y, en consecuencia, esperamos aumento en la tasa de mortalidad general. Sin embargo, los municipios de Luvianos, Amatepec, Otzoloapan, Tlataya y Tejupilco deben considerarse prioritarios para atender este sector de actividad económica, porque registraron los coeficientes más altos $(2,68-3,75)$ con un nivel de confianza de 0,95 y 0,975 respectivamente. En contraste, treinta municipios localizados al centro y suroriente principalmente resultaron con relación negativa. Sus coeficientes tienen valores negativos, lo que indica que, con una disminución en el porcentaje de población ocupada en el sector comercio, la tasa de mortalidad 
general aumenta. Esto quiere decir que, aunque existe una disminución, también se espera aumento en la TMG, por lo que, también deben ser considerados prioritarios. Los que presentan las condiciones más negativas son Tepetlixpa, Ecatzingo, Ozumba, Atlautla y Juchitepec porque registraron los coeficientes más altos $(-5,17,-4,43)$ con un nivel de confianza de 0,95 (gráfico 11).

Gráfico 11. Estado de México: GWR. Tasa de mortalidad general con respecto a la distribución porcentual según sector de actividad económica: comercio (población ocupada), 2015

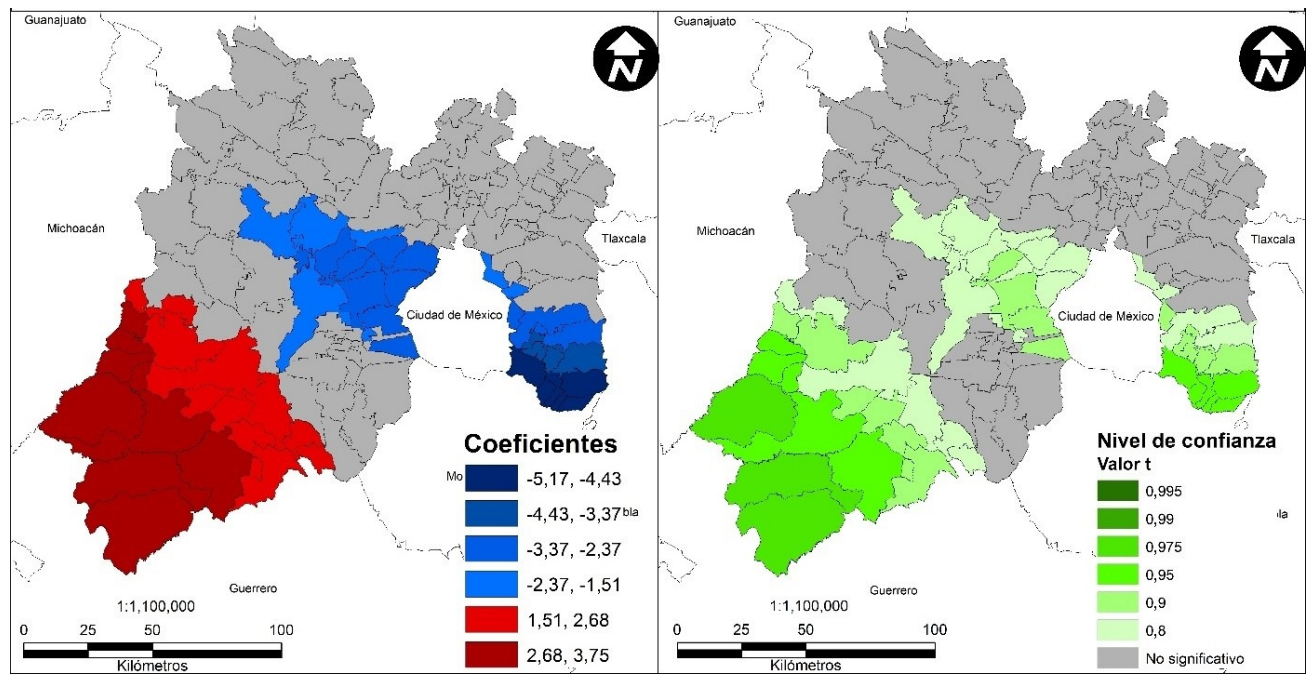

Fuente: elaboración propia en los software GWR4 y ArcMap.

\subsection{Tasa de mortalidad general con respecto a la distribución porcentual según sector de actividad económica: servicios (población ocupada), 2015}

El porcentaje de población ocupada en el sector servicios tuvo una relación positiva en veintitrés municipios localizados al suroccidente de la entidad. La fluctuación en sus coeficientes resultó con valor positivo, lo que indica que varía directamente con la mortalidad y, en consecuencia, esperamos aumento en la tasa de mortalidad general. Sin embargo, los municipios de Luvianos, Amatepec, Otzoloapan, Tlataya y Tejupilco deben considerarse prioritarios para atender este sector de actividad económica, porque registraron los coeficientes más altos $(5,96-7,34)$ con un nivel de confianza de 0,99. En contraste, veintinueve municipios localizados al centro y suroriente resultaron con relación negativa. Sus coeficientes tienen valores negativos, lo que indica que, con una disminución en el porcentaje de población ocupada en el sector servicios, la tasa de mortalidad general aumenta. Esto quiere 
decir que, aunque existe una disminución también, se espera aumento en la TMG, por lo que deben ser considerados prioritarios. Los que presentan las condiciones más negativas son Tepetlixpa, Ecatzingo, Ozumba, Atlautla y Juchitepec porque registraron los coeficientes más altos $(-8,38,-7,21)$ con un nivel de confianza de 0,95 (gráfico 12).

Gráfico 12. Estado de México: GWR. Tasa de mortalidad general con respecto a la distribución porcentual según sector de actividad económica: servicios (población ocupada), 2015

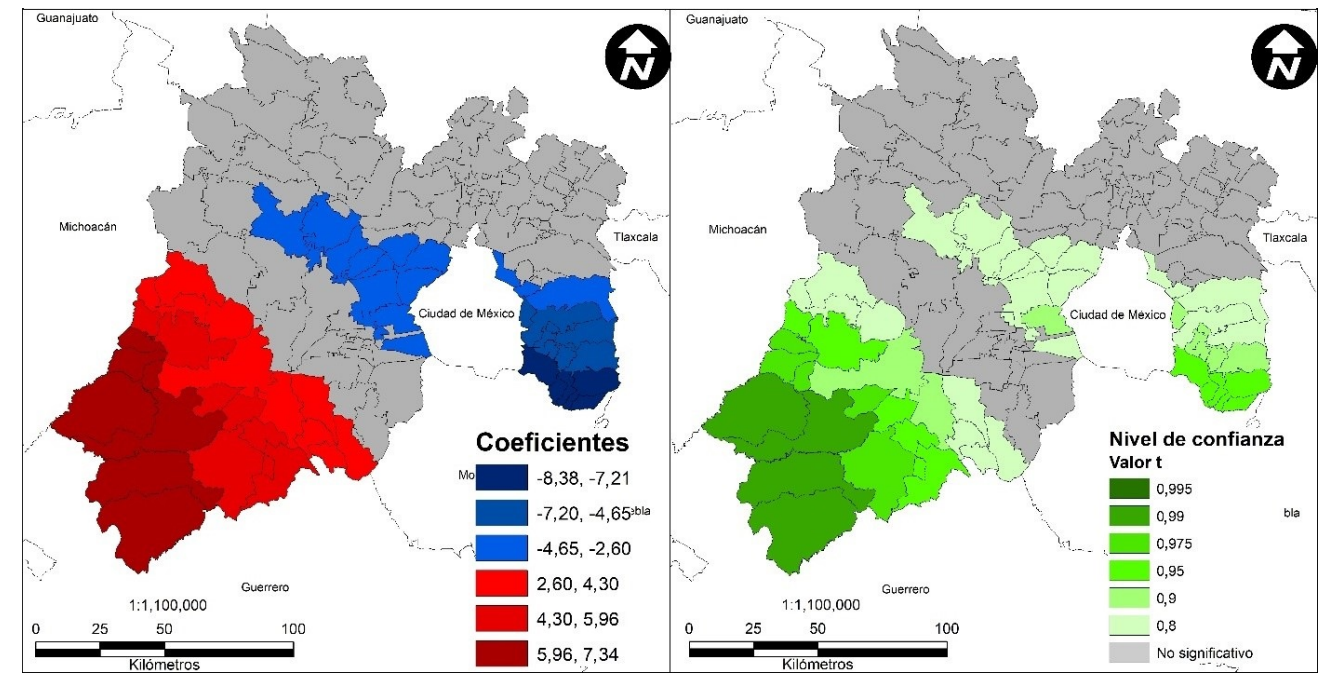

Fuente: elaboración propia en los software GWR4 y ArcMap.

3.10 Tasa de mortalidad general con respecto a la distribución porcentual según ingreso por trabajo: de uno a dos salarios mínimos mensuales (población ocupada), 2015

El mayor porcentaje de la población ocupada $(35,7 \%)$ se encuentra en el rango de uno a dos salarios mínimos mensuales, lo que va de 3.240 a 6.480 pesos mexicanos al 2019, seguidos de un 22,6 \% que cuenta con un ingreso menor a un salario (Conasami, 2020). A diferencia de los resultados anteriores, aquí no se muestran valores bajos, lo que significa que la relación entre estas dos variables es solamente positiva.

El porcentaje de población con ingresos de entre uno y dos salarios mínimos mensuales tuvo una relación positiva en cincuenta y nueve municipios localizados al nororiente, centroriente y suroriente de la entidad. La fluctuación en sus coeficientes resultó con valor positivo, lo que indica que, varía directamente con la mortalidad $\mathrm{y}$, en consecuencia, esperamos aumento en la tasa de mortalidad general. Sin 
embargo, los municipios de Huixquilucan, Xalatlaco, Ocoyoacac, Tianguistenco y Ocuilán deben considerarse prioritarios para atender este sector de la población, porque registraron los coeficientes más altos $(0,54-0,65)$ con un nivel de confianza de 0,95 (gráfico 13).

Gráfico 13. Estado de México: GWR. Tasa de mortalidad general con respecto a la distribución porcentual según ingreso por trabajo: más de uno a dos salarios mínimos mensuales (población ocupada), 2015

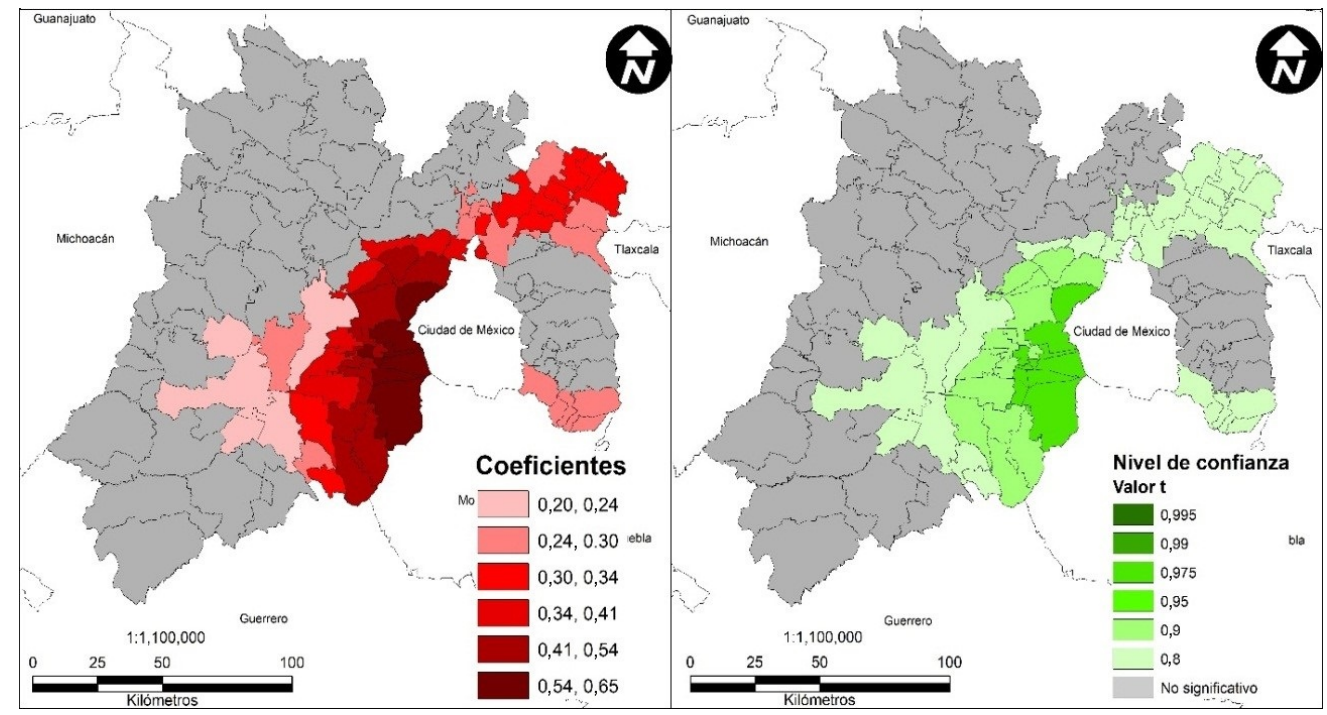

Fuente: elaboración propia en los software GWR4 y ArcMap.

\section{CONCLUSIONES}

La variabilidad espacial de la tasa de mortalidad general y las características económicas de la población ocupada es heterogénea, y cada característica presenta su propio patrón de distribución. De esta manera, se muestran los municipios prioritarios para implementar de políticas públicas económicas que incidan en la disminución de la mortalidad general.

Existen desigualdades territoriales en cuanto a la distribución porcentual según ocupación de la población (funcionarios, profesionistas, técnicos, administrativos, agropecuarios, trabajadores en la industria y comerciantes) y la tasa de mortalidad general. En la mayoría de los casos, los municipios localizados al centro y suroriente están siendo afectados por presentar una relación positiva entre la ocupación de la población y la mortalidad, lo que trae como consecuencia un aumento en 
la tasa de mortalidad general. Sucede lo contrario en los municipios ubicados al suroccidente principalmente, los cuales registraron una relación negativa que indica una disminución en la ocupación de la población, pero también se espera aumento en la tasa de mortalidad general.

Por lo anterior, los municipios que registaron los coeficientes más altos tanto positivos como negativos deben considerarse prioritarios para atender cada uno de los sectores de trabajadores, para implementar medidas o políticas económicas que reduzcan la mortalidad.

La población ocupada según el sector de actividad económica (primario, secundario, comercio y servicios) está siendo afectada en tres zonas principalmente. Los municipios localizados al suroccidente registraron una relación positiva entre el sector al que pertenecen y la mortalidad, lo que trae consigo un aumento en la tasa de mortalidad. Cabe señalar que la mayoría de estos son rurales. En cambio, los municipios ubicados en el centro y suroriente registraron una relación negativa que indica una disminución del porcentaje de población en cada sector, pero también se espera aumento en la tasa de mortalidad general.

Debido a ello, los municipios que registraron los coeficientes más elevados tanto positivos como negativos en las tres zonas localizadas como afectadas, deben considerarse prioritarios para atender a la población en cada sector de actividad económica. Además, es necesario identificar las deficiencias y potencialidades de cada lugar para proponer políticas económicas y fortalecer cada sector en pro de la disminución en las defunciones.

La población ocupada que recibe un ingreso mensual de entre uno y dos salarios mínimos tuvo una relación positiva, por lo cual se espera un aumento en la tasa de mortalidad general. Por ello, los municipios que registraron los coeficientes más altos y que se localizan en centroriente deben considerarse prioritarios para atender el sector de población con estos ingresos, debido a que resultó con variabilidad espacial positiva, es decir, con un aumento en la TMG en comparación con la población que tiene ingresos de uno a dos salarios mínimos.

\section{BIBLIOGRAFÍA}

Barcellos, Christovam; Buzai, Gustavo y Santana, Paula (2018). Geografía de la salud: bases y actualidad. En: Salud Colectiva, vol. 14, n. ${ }^{\circ}$ 1, p. 1-4. DOI: https://doi.org/10.18294/sc.2018.1763

Barcellos, Christovam (2003). Unidades y escalas en los análisis espaciales en salud. En: Revista

Cubana de Salud Pública, vol. 29, n. 4, p. 307-303. 
Buzai, Gustavo (2015). Análisis espacial en geografía de la salud: resoluciones con Sistemas de Información Geográfica. Buenos Aires: Lugar Editorial, 242p.

Carneiro de Oliveira, Danila; Salgado Barreira, Ángel; Taracido Trunk, Margarita y Figueiras Guzmán, Adolfo (2010). Efecto de las desigualdades socioeconómicas en la mortalidad de la ciudad de Fortaleza, Ceará, Brasil durante el año 2007. En: Revista Española de Salud Pública, vol. 84, p. 441-450.

Casi Casanellas, Alfonso y Moreno Iribas, Conchi (1992). Nivel socioeconómico y mortalidad. En: Sanidad e Higiene Pública, vol. 66, n.ำ 1, p. 17-28.

Conabio - Comisión Nacional para el Conocimiento y Uso de la Biodiversidad — (2020). Portal de geoinformación 2020. https://bit.ly/2OwFw1J

Conasami —Comisión Nacional de los Salarios Mínimos- (2020). Salarios mínimos 2020. https://bit.ly/3jbh9oi

Fotheringham, Alexander; Brunsdon, Chris y Charlton, Martin (2002). Geographically Weighted Regression: The Analysis of Spatially Varying Relationships. Chichester: Wiley, 284p.

Inegi —Instituto Nacional de Estadística, Geografía e Informática- (2020). Clasificación mexicana de ocupaciones, CMO-Histórica. https://www.inegi.org.mx/contenidos/clasificadoresycatalogos/doc/clasificacion_mexicana_de_ocupaciones_vol_i.pdf

Inegi —Instituto Nacional de Estadística, Geografía e Informática — (2018). Sistema nacional de clasificación de ocupaciones 2018. Recuperado de https://bit.ly/3fFjaqz

Inafed —Instituto Nacional para el Federalismo y Desarrollo Municipal— (2015). Datos del medio físico. https://bit.ly/2DHBAsz

Mackenbach, Johan; Bopp, Matthias; Deboosere, Patrick; Kovacs, Katalin; Leinsalu, Mall; Martikainen, Pekka y de Gelder, Rianne (2017). Determinants of the magnitude of socioeconomic inequalities in mortality: A study of 17 European countries. En: Health and Place, vol. 47, p. 44-53. DOI: https://doi.org/10.1016/j.healthplace.2017.07. $\overline{005}$

Olivera, Ana (1993). Geografía de la salud. Madrid: Síntesis, 160p.

Perdomo, Lina María 8y Cuartas, Daniel Elías (2010). Encuentro de la geografía y la medicina, una visión entre el pasado y el presente como abordaje para el desarrollo de la distribución de las malformaciones congénitas mayores en Cali. https://geografiadelasalud.blogia.com/

Ramírez Mita, Liliana (2005). La moderna geografía de la salud y las tecnologías de la información geográfica. En: Investigaciones y Ensayos Geográficos, n. ${ }^{\circ}$ 4, p. 53-64.

Rojo, José Manuel (2007). Regresión lineal múltiple. Madrid: Instituto de Economía y Geografía, 31p.

Sánchez, Christian Iván (2019). Análisis espacial de la transición epidemiológica en la mortalidad infantil en el Estado de México. Tesis para optar al título de Maestro en Análisis Espacial y Geoinformática. Maestría en Análisis Espacial y Geoinformática, Universidad Autónoma del Estado de México, México, 114p. 
Santana, Marcela; Rosales, Elsa y Santana, Giovanna (2016). Geografía de la salud: antecedentes, aspectos teóricos y perspectivas. En: Oliveira, José y Souza, Geraldo (Coords.). Geografía da saúde: ambientes e sujeitos sociais no mundo globalizado. Manaos: Editora da Universidade Federal do Amazonas, p. 95-128.

Sinais - Sistema Nacional de Información en Salud- (2015). Datos de mortalidad de la Secretaria de Salud. http://www.dgis.salud.gob.mx/contenidos/basesdedatos/ bdcdefuncionesgobmx.htm 